\title{
The use of online discussion board and blogs to enhance History student teachers' Work Integrated Learning (WIL)
}

\author{
DOI: http://dx.doi.org/10.17159/2223-0386/2021/n25a3
}

\section{Valencia Mabalane}

University of Johannesburg, Johannesburg, South Africa

valenciam@uj.ac.za

Orcid: 0000-0003-4492-0098

\section{Abstract}

The paper reports on research on History student teachers' enhancement of Work Integrated Learning (WIL) using online tools like a discussion board and blogs. It draws on the enhancement programme planned for the History student teachers - 78 Bachelor of Education students (BEd) 4th-year students and 28 Post-Graduate Certificate in Education (PGCE) students who were expected to integrate technological tools in their teaching during WIL; some of them, mostly PGCE students lacked the necessary Pedagogical Content Knowledge (PCK) in this regard. Thus, the main purpose of this study was to explore the extent to which the online discussion board and blogs enhanced student teachers' classroom practice during WIL. The theoretical lens that informed this study was the five-factor model of mentoring for effective teaching that underpinned the need for improved support and mentoring by the History student teachers: personal attributes, system requirements, pedagogical knowledge, modelling, and feedback. Qualitative research methods and purposive sampling were used. The data was analysed using content analysis as per the five-factor model of mentoring for effective teaching. The findings revealed that student teachers responded overwhelmingly positively to the use of the online tools. They also revealed that the one-and-a-half-hour face-to-face debriefing was not acceptable to the majority of the participants. Most of them felt that it was just a formality and failed to address their immediate needs compared to being mentored online by their peers. In light of these findings, the study suggests that the usage of an online discussion board and blogs in mentoring and encouraging the improvement of student teachers' PCK should be considered and included when planning WIL programmes. 
Keywords: History; Work Integrated Learning; Reflection; Discussion board; Blogs; Fivefactor model of mentoring for effective teaching. 


\section{Introduction}

This paper reports on the experiences of Bachelor of Education students (BEd) $4^{\text {th }}$-year students and Postgraduate Certificate in Education (PGCE) History students in online debriefing sessions. This study also explores how these History student-teachers reflected on their experiences of online discussion board and blogs as support and mentoring devices during Work Integrated Learning (WIL) or teaching practice. The two will be used interchangeably in this article. Student teachers had to reflect on how they experienced teaching in a real context.

Teaching is perceived as a complex task that is thought-provoking and challenging, both intellectually and emotionally. Teachers, in this case, student teachers, must possess knowledge about the subject being taught, the curriculum, suitable teaching and learning strategies or methods, and the abilities, interests, and personalities of the learners. More so, teaching, for the first time, has never been easy for anyone especially the student teachers who have to transit from being "learners" themselves to being "teachers". This is supported by Strom and Martin (2016) who argued that what student teachers gained from the lectures does not automatically transfer into classroom practices, thus they advocate that several enabling and compelling features and elements influence the pedagogical decision making and the presentation of teaching practices. This means that most student teachers start understanding real and authentic teaching during the classroom interactions with the learners and content. It is also during this time that their true selves are created in the classroom as they use different teaching strategies that define their teaching philosophy.

Furthermore, Britzman (1991:8) added that "Learning to teach - like teaching itself is always the process of becoming: a time of formation and transformation, of scrutiny into what one is doing, and who one can become". He also argued that when we learn to teach, we do not just apply decontextualised skills or mirror prearranged images, but we put into action all that was learnt in the past, present, and future in a dynamic way, and this makes teaching complex as no one knows what to expect. Oduaran and Mokoena (2015, in Taole, 2015) also argued that teaching is complex, thus it is critical that teacher programmes should identify and document specific and general forms of effective teacher behaviour that could enhance student performance and good teaching skills. They also attributed the complexity to the fact that all teachers including student teachers must possess the ability to accommodate leaners' varied temperaments and personalities, design and manage the classroom activities, master technology, and, at the same time, be reflective teachers who are able to change and continually develop within their subjects. 
Accordingly, to do all that has been mentioned above, teachers require high quality characteristics and skills from their practice, in other words, teacher professional knowledge (Darling-Hammond, 2006). Korthagen (2010) also supported this view by stating that the sheer complexity and difficulties of classroom life require an integrated understanding of the relationship between teachers' changing awareness of classroom activity, the increasing awareness of concepts and principles that are formed in practice, and the theoretical understandings that are produced from a range of different sources. In other words, it calls for professional learning, which focuses on central and vital all-inclusive transformations and not just the superficial or shallow acquisition of ideas, information, and skills which sometimes takes place in the lectures. The implication drawn from all the above authors is that teaching is a complex task that needs innovative training that can assist in the enhancement of student teachers' performance in the classroom.

Student teachers have to be active participants in constructing their identity and PCK as they proceed through their training. These expectations have to do with how they teach as student teachers, how they interact with learners, the advancement of learning, how they construct and manage the classroom activities, and what level of PCK they have (Darling-Hammond, 2006). More so, teachers must possess the ability to accommodate every learner's temperament and personality. Furthermore, Hudson (2010) posited that since teaching is an interpersonal, emotional, and social profession, teachers should ensure that they are competent in twenty-first century technologies to support and mentor others, over and above formal teaching and learning. Additionally, Shulman (1986) asserted that for teaching to be of high quality, teachers have to possess more intricate, elaborate, and professional knowledge, which is core to professional development of a teacher, which is PCK.

Desimone (2009) argued that teachers' professional learning should be characterised by active learning, reflective thinking, and collective participation instead of passive learning. Thus, the context of the school plays a role in shaping and reshaping their understanding of teaching and (re)construction and deconstruction of their professional identities (Flores \& Day, 2006). In addition, student teachers' transition to a different environment may cause considerable anxiety because of the unfamiliar context of the classroom, and the taking on of the different status of being a teacher with high expectations from learners, the school, and their tertiary institutions. When the teachers move from preservice teacher education to the actual teaching environment, they are often overwhelmed by the shock of entering the workplace when they are in a classroom and have to be with children for the whole day. Knowing that they are responsible for the children's wellbeing and their learning can 
be intimidating to new student teachers as they begin to perceive themselves no longer as students but as practitioners (Van Veen, Sleegers \& Van de Ven, 2005; Beauchamp \& Thomas, 2006). This then calls for student teachers to be equipped with both the conceptual knowledge - which is disciplinary knowledge or content, and contextual knowledge - the didactics and practical knowledge aspects necessary for classroom practice (Dreyer, 2015, in Taole, 2015).

I therefore conclude that student teachers must be supported with effective reflection methods and tools appropriate to maximise their capabilities and skills to function in diverse classroom environments. The study was designed to explore whether the use of dialogic online tools might aid the achievement of these objectives. Traditional training and preparation should be minimised to include online reflections to facilitate and encourage student teachers' cooperation, collaboration, and group discussion (Rytivaara \& Kershner, 2012). Currently student teachers only reflect at the end of WIL, giving the holistic reflection of their experiences. Similarly, Mahlangu (2018) supported the preceding conclusion by asserting that technology can be implemented as a tool to learn and can be utilised to eradicate the barriers and challenges present in students learning off campus. Bell, Douce, Caeiro, Teixeira, Martín-Aranda and Oto (2017) added that employment and application of technological tools affords a consistent delivery of content, because online materials such as videos can be pre-recorded and shared with the rest of the class online. Furthermore, students are afforded the means of supporting learning processes, cooperation, and flexibility. Teacher education should also make wider distribution of education and training possible and allow for more effective assessment of content and skills. It is against this backdrop that online affordances were implemented to assist student teachers to reflect collectively with their peers on their WIL experiences as a means of coping with the complexities of the teaching. I contend that this gap exists in how most teacher education institutions use reflection tasks. Very few, if any, teachers in South African education simultaneously use both the discussion board and blogs to support student teachers during WIL reflection debriefing sessions.

Thus, the research question of this study is: "To what extent do an online discussion board and blogs enhance reflective practices of student teachers during WIL?"

The aim was to explore the extent to which the online discussion board and blogs enhanced reflective practices of student teachers during WIL. 


\section{Work-Integrated learning (WIL)}

WIL is an indispensable part of teacher education which is compulsory and serves as a means of assisting student teachers to experience the classroom practice and atmosphere before starting their careers (Moosa, 2019). Through teaching practice, student teachers are afforded an opportunity to practice what they learnt theoretically during lectures in an authentic classroom context. The Council on Higher Education (2011:4) defined WIL as:

an approach to career-focused education that includes classroom-based and workplacebased forms of learning ... an educational approach that aligns academic and workplace practices for the mutual benefit of students and workplaces ... WIL is primarily intended to enhance student learning.

WIL plays an integral role in the formation of the student teachers' professional identities, and it is an authentic space for them to experience the real world of teaching. It also serves as an ideal space for the student teachers to practise becoming effective teachers. During WIL, student teachers are afforded the time to interact with the school, staff, learners, and other role players. Du Plessis $(2010 ; 2013)$ described teaching practice as a method of WIL wherein all aspects of student teachers' teaching practices are expected to be based on the main structures of WIL. Thus, WIL and teaching practice are usually used interchangeably with concepts such as practicum or teaching experience. Furthermore, the student teachers are also afforded an opportunity to learn from observing their mentor teachers and intervening in and influencing the classroom activities as a whole (Milne, 2006; Moosa, 2019). Thus, the Department of Higher Education set teaching practice as compulsory for all student teachers, with the duration ranging from 20 weeks for BEd and 10 weeks for PGCE students under the supervision of experienced mentor teachers (Du Plessis, 2010; Dreyer, 2015, in Taole, 2015).

Unfortunately, WIL issues in South Africa are intricate and complex because of how they are organised. Each institution determines how and when their WIL will be conducted. There has not been agreement and any similarity in how student teachers should do their WIL or interact with their mentors. Different universities design their own rules and guidelines of how student teachers should do WIL and be mentored (Moosa, 2019). This dissimilarity prompted the university in question to introduce the debriefing - a face-toface group reflection - to deal with any challenges the student teachers might experience during WIL. Consequently, the researcher found it critical to use the online tools such as 
the discussion board and blogs for student teachers to reflect on their classroom practice. As a result, student teachers were afforded the opportunity to tap into and uncover challenging and problematic issues that cannot be addressed in a one and a half hour faceto-face debriefing session.

\section{Context of the study}

This study was conducted at one university in Gauteng. The focus was on the History student teachers - Bachelor of Education $4^{\text {th }}$-year students (BEd) and PGCE students. These student teachers were required to report back on campus three weeks after their seven-week WIL to debrief and deal with challenges they experienced. The debriefing was scheduled for one and a half hours, and the module lecturer had to deal with all the issues raised within that time. Student teachers had many challenges, and the time was not sufficient to deal with all the different issues or to give satisfactory advice and feedback. This debriefing session was also formal in nature and some student teachers did not want to open up about their challenges in front of their peers.

Thus, the introduction of the online discussion board and blogs from 2016 to 2020 was to afford the student teachers an innovative opportunity to talk and interact with their peers and the lecturer - the researcher - without fear of being ridiculed or shamed. The online discussion and blogs were introduced from the first week (see below) of WIL with the student teachers' reception to the seventh and last week of WIL. Student teachers submitted the reflection task once a week. The study reports on the $78 \mathrm{BEd}$ students divided into six diversified groups of 10 and two of nine - and 28 PGCE students - divided into four diversified groups of eight History Further Education and Training (FET) student teachers. The division of the students were to assist with manageable groups and to ensure diversification of ideas. Thus, the implementation of online mentoring and debriefing was used during the entire seven-week WIL for discussion and was facilitated through different tasks and discussions with the student teachers. The blog section was used to answer the tasks and the discussion board was for students to share and discuss aspects of interest, and the highlights and challenges relevant to teaching and learning. Below are examples of when and how the entries were made: 


\section{Week 1 Blog - Task 1}

\section{Reflection on the first three days of observation}

1. Reception by the school: Positive and negative aspects.

2. $1^{\text {st }}$ day of observation of your mentor teacher. Focus on the following:

- Teaching strategies

- Use of examples and illustrations

- Incorporation of media

- Questioning skills

- Learners' behaviour

- What have you learnt from aspects in number 2 that will benefit your teaching practice and enhance your teaching as a student teacher?

- How can we assist you with your challenges?

- Comment on the reflection of all your group members.

\section{Week 2 Blog - Task 2}

\section{Reflection on personal teaching}

- Share your first day experience of teaching and focus on the following:

- Lesson planning

- PCK

- Questioning

- Classroom management

- Challenges, experiences, and areas to be improved

- Need for scaffolding

- Give advice where necessary on what members of your group have posted.

\section{Week 4 Blog - Task 3}

\section{Reflection on personal teaching}

- Share your five days' experience:

- Share the highlight of the week with regard to your teaching

- How did you address the following issues?

- Diversity

- Learning styles 
- Controversial issues

- Dealing with biasness

- Challenges experiences and areas to be improved

- Need for scaffolding

- Give advice where necessary on what members of your group have posted.

\section{Week 5 Blog - Task 4}

\section{Reflection on personal teaching}

- Share with us any section you taught - what went right and what went wrong?

- Teaching strategies and media used

- Assessment

- Teaching and learning barriers

- Any achievements or challenges

- Give advice where necessary on what members of your group have posted.

\section{Week 6-7 Online Assignment - Task 5}

Individual task: Reflection on the seven weeks of WIL

- Reflect on your teaching experience as a whole for the seven weeks.

Focus:

- Philosophy of teaching, worldview - need for change.

- Compare your philosophy of teaching to the gained knowledge and experience.

- What will I change/ improve?

- Do you think you were sufficiently equipped with theory and practice (skills) during the seven weeks to be able to practice as a teacher? Substantiate your answer.

- Any highlights and/or additional comment.

- Submit on the online link.

\section{Theoretical framework}

The theoretical lens that informed this article was the five-factor model of mentoring for effective teaching by Hudson $(2007 ; 2010)$. The five-factor model includes personal 
attributes, system requirements, pedagogical knowledge, modelling, and feedback (Hudson, 2007; 2010). According to Sempowicz and Hudson (2011:2), "this model has associated attributes and practices which provide a theoretical framework for gathering data around mentoring, and are specifically used for interpreting and understanding the mentoring for effective classroom management”. This theoretical framework underpinned the need for improved support and mentoring by the History student teachers. In this case, the lecturer and fellow student teachers served as mentors. Fellow student teachers and the lecturer joined hands in responding to the needs of each student teacher using online tools. The five factors of mentoring for effective teaching are discussed below.

Personal attributes: Support was given to the mentees by scaffolding them and providing guidance through interaction and communicating, listening, and paying attention. The mentor's personal qualities and characteristics were a tool for encouraging the mentees' reflection on their classroom practice. The mentor also built positive attitudes, imparted confidence, and developed a positive self-concept in mentees. In this study, the student teachers were supported and guided by creating an opportunity to communicate via a discussion board and blogs. The student teachers took the lecturer into their confidence by openly having online dialogue without fear or shame. In cases where an issue was too sensitive, student teachers were allowed to submit anonymously. They received attention and support through positive comments from their lecturer and peers through the discussion board.

System requirements: The aims of mentoring, policies, and the teaching and learning plan as a means of allowing a conducive learning environment and curricula required by an education system must be clearly articulated. Even so, pedagogical knowledge is essential for executing the system requirements. Thus, the aim and purpose of the online debriefing sessions were clearly articulated to student teachers as "a means of enhancing student-teachers' WIL”. The student teachers were given the tasks which hinged on the curriculum for BEd $4^{\text {th }}$-year students and PGCE students. Furthermore, the student teachers were given weekly tasks based on the pedagogical knowledge. Issues such as biasness, controversial issues, and emotive issues in History were discussed. The Curriculum and Assessment Policy Statement (CAPS) FET formed the basis of what was discussed. The tasks given also emphasised skills such as classroom management, using essential questions, and managing student behaviour. Pedagogical knowledge: The focus was on the mentor's planning of teaching and 
setting scheduled lessons for the mentee. Student teachers' plans and tasks were designed each week; in this case, five weeks, to be precise, with clearly articulated tasks and due dates. Furthermore, preparation for teaching needed to be discussed, including the use of resources. Since student teachers had to do their WIL in the geographical area of the institution, it was easier for them to use the institution's resources such as the library, computers, and the Wi-Fi. The skills and teaching strategies were checked including the student teachers' content knowledge to ensure that they did not diverge from the CAPS requirements and phase and grade level. Thus, the key concepts in the teaching and learning of History in the FET phase Grades 10 to 12 were emphasised. The student teachers had to respond or comment on their peers' posts using the procedural or substantive concepts as prescribed in the teaching of History.

The nature of the online debriefing itself equipped student teachers with problemsolving skills because it allowed them to deal with their challenges and those of their fellow student teachers as they engaged online. Furthermore, student teachers learnt from the varied assessment and teaching strategies, use of resources, and different ways of managing their classroom as they engaged in the blogs and discussion board with their peers.

Modelling: Exhibiting and demonstration of teaching and the classroom practice is important for student teachers. The mentor has to show the mentee how to encourage the positive rapport between teacher and learner therefore creating a relationship as well as modelling proper respectful classroom language that encourages mutual respect. The phase and subject knowledge also have to be demonstrated. Thus, the student teachers, with the permission of the mentor teacher, recorded the lessons during the first week of observation. These were analysed online, and different opinions were given by their peers. The issues of diversity were observed, and the use of unbiased language was analysed as per the History curriculum. Furthermore, the student teachers had to analyse and evaluate video-recorded lessons by practising teachers who were former students of the institution.

Feedback: The need for effective feedback characterised by articulated expectations and advice was necessary in this section. Feedback was provided as student teachers and the lecturer commented on the posts of those who posted. Concise and detailed feedback was provided by group members, by other groups, and the lecturer. The feedback was done timeously and showed pedagogic knowledge based on the tasks 
given. The student teachers were also afforded an opportunity to consolidate and share their experiences and future expectations.

\section{Data collection methods and analysis}

The five-factor model attributes and practices in relation to debriefing informed data gathering in all areas of the study. All the questions asked to the participants were based on the five-factor model to explore how student teachers experienced the online debriefing.

The study adopted the qualitative research paradigm in order to understand the feelings of the student teachers and gather their opinions and personal experiences (Creswell, 2007). The student teachers were required to report back on campus three weeks after their seven weeks' WIL to debrief and deal with challenges they experienced in the weeks at their different WIL sites. Thus, the interpretive paradigm was used to give the researcher an opportunity to interpret and understand the experiences of the History student teachers with regard to the benefits and impact of the online enhancement programme (Saunders, Lewis \& Thornhill, 2009). This was also an attempt to equip student teachers with the necessary mentoring, support, and guidance in reflective practice during the seven weeks' WIL with regard to History FET PCK. FET PCK, as a process of enquiry, addresses the eight skills as stipulated in the CAPS document as well as the substantive first-order concepts and the five procedural second-order concepts, namely: historical sources and evidence; multi-perspectivity; cause and effect; change and continuity; and time and chronology. All the content has to be facilitated through questions conveying history as an enquiry and not just received knowledge, as historical knowledge is open-ended, debated, and changeable. By ensuring active participation of learners, facilitating history lessons around the intrigue of questions, and encouraging research, investigation and interpretation are conducted and directed through questions (Department of Education, 2011). The PCK is the same with minimal differences in the senior phase and is combined with Geography - referred to as Social Sciences - and emphasises memorisation of all content and includes a research project. Permission to use the students' content was granted by the students themselves and the university faculty ethics committee. The comprehensive clearance certificate Sem 2-2020-015 under the theme "Student-teachers' identity and the teaching of high school History" was granted.

The selection of the study sample was done by purposive sampling which is a nonprobability sampling method (Saunders et al., 2009). All the $4^{\text {th }}$-year BEd and PGCE student teachers in the History module participated, and they were diversified in terms 
of gender, language, race, and socioeconomic status, to name a few (Kvale, 2007). The diversity of the sample helped in accessing different views and experiences of $78 \mathrm{BEd}$ students - divided into six diversified groups of 10 and two of nine - and 28 PGCE students - divided into four diversified groups of eight History Further Education and Training (FET) student teachers. Data was collected by means of observing micro lessons and lessons presented during WIL by the researcher. The other method used was analysis of documents by the lecturer, such as lesson plans through marking and comparing to the lesson presented, marking and analysing discussion board posts, and submitted tasks on blogs. Lastly, semi-structured, face-to-face, individual interviews were used for each group or individual as a means to follow up what was observed or posted on the discussion board and blogs. These interviews were conducted by the lecturer after the seven weeks of WIL, observations of micro lessons, and analysis of all documents.

The researcher had access to information-rich cases because the student teachers were directly involved with the phenomenon, and were able to reflect on personal accounts, thoughts, and perceptions of the online support versus the face-to-face debriefing and the impact on their WIL. Data analysis using content analysis based on the five-factor model of mentoring was used (Merriam, 2002; Marshall \& Rossman, 2016). All the data from the observations, analysed lesson plans, online posts, and interviews were analysed using the content analysis method. Each student teacher's responses were analysed separately in order to draw out their feelings, experiences, and uniqueness of their meaning (Ryan \& Bernard, 2003; Gibbs, 2007). The recurring themes were identified from the student teachers' data and later classified as the final emerging themes. These were grouped according to the fivefactor model for mentoring, namely personal attributes, system requirements, pedagogical knowledge, modelling, and feedback (Hudson, 2007; 2010).

\section{Findings}

All the findings were based on the qualitative design only and no statistics were gathered from the interviews. Again, most of the participants agreed that the online support benefited them to a certain extent although it was sometimes time consuming. The following question was asked to get participants' general feelings and experiences about the online discussion board and the blogging: "Based on your observation and experiences, how would you compare the online discussion board and the blogging to face-to-face one day debriefing?" Almost all the participants (98\%) agreed that it was beneficial because it afforded them time to work from the comfort of their different spaces and homes, with $2 \%$ 
unsure of the answer.

$R V$ : I just feel that the faculty doesn't take us as students serious, what can one say in one hour and few minutes about our burning issues? Schools are not easy and it is tough out there ... we must be given enough time to talk about our problems.

PD1 hailed the importance of the online debriefing as follows:

Thank you for asking, Dr. I am so empowered as a result of the online debriefing, and have since improved, and the standard of my teaching is high. I found so many benefits with it, because I came to realise that as students we go through the same challenges. Before the debriefing, I always thought I was the only one with teaching practice problems ... as soon as my classmate commented and wrote about their experiences, I came to realise that it is all of us and not me alone.

$Z K$ : The online debriefing is a blessing to me because I can talk without being intimidated, but it takes away data and money. It also gives me an opportunity to guide my peers and to talk to those students I have never spoken too before... we are able to help each other as students and not depend on the lecturer with respect, guided by the questions. ... I can also share my great achievements of the day of in the discussion board.

However, one student said:

Jam: The online debriefing is better than the face-to-face, but it demands too much from students because we must always be on the computer unnecessary so ... it is just a waste of time and resources.

\section{Personal attributes}

To understand the development of personal attributes the student teachers were asked three questions:

- What is your understanding of personal attributes?

- What personal attributes do you think History teachers should possess? 
- To what extent do you think your participation in the online discussion board and blogging was able to help you gain the History teachers' attributes you mentioned?

Varied responses showed understanding and misunderstanding of the personal attributes needed: $85 \%$ showed understanding, while $17 \%$ showed partial understanding. When it came to the second question, participants discussed aspects such as patience, love, courage, self-control, self-regulation, care, confidence, the ability to withstand challenges and to accept failure, collegiality, positive self-concept, good character versus bad character, and good traits. Lastly, with the third question, all the participants indicated that they had developed most of the attributes they mentioned.

\section{Understanding the importance of personal attributes as a teacher}

Student teachers were able to transform their personal attributes as a result of this programme. All of them, especially PGCE student teachers reported that their misguided and mistaken conceptions about the attributes of a teacher had changed and improved. They were impacted positively by understanding the characteristics needed to be a teacher. Their views were demystified and elucidated as they engaged in the online discussions. One participant reported the following when asked: "To what extent do you think your participation on the online discussion board and blogging was able to help you gain the History teachers' attributes you mentioned?"

JJ: A lot, a lot, mam. It has afforded me an opportunity to know about what it means to be a teacher and how I should behave. ... I have learnt that being a teacher needs one to love, care and be humane. Promote human ... and understanding, forgiving and self-care.

Hudson (2013:107) supported Evertson and Smithey (2000) by stating that, "There is ample evidence that effective mentoring can have a positive effect on a preservice teacher's pedagogical practices. This evidence extends to advancing specific teaching practices such as managing students and their behaviours in classroom”. In other words, student teachers are afforded an opportunity to build the characteristics that will enable them to deal with classroom challenges. 


\section{Improved self-concept and confidence}

Again, most student teachers who had previously received negative and destructive criticism from teachers reported that they found it difficult to trust in their abilities and to trust others. The results were as follows:

- $69 \%$ of them indicated that their experiences with mentors and lecturers were so bad that their self-concept was eroded and they masked it by being aggressive or pretending to be shy. Others just avoided issues or talking to those who posed a threat to them.

- $11 \%$ indicated that their loss of personal confidence came as a result of the criticism from fellow student teachers.

- $20 \%$ indicated that talking to peers without being seen had actually enhanced their confidence.

LP: It is important for a teacher to know who he is, before he can help learners with their identities. Teachers must be conversant with their personality especially being confident and controlling emotions. Through interacting with my classmates, I was able to face my fears of lacking confidence especially with regard to English. It helped me to communicate well, contribute to fellow students and to articulate my feeling without fear of being ridiculed.

GR4: I have learnt that being emotionally aware of my emotions can help me communicate effectively.

By the same token, Goel and Goel (2010:24) emphasised what the participants stated, namely that:

Teacher education for preparing humane and professional teachers needs to be holistic. Along with content and methodology, there is also a need to integrate emotional competencies, such as self-awareness and self-management, social sensitivity and social management. It is also essential to integrate life skills, such as self-awareness, empathy, interpersonal relationships, effective communication, critical thinking, creative thinking, decision-making, problemsolving, and coping up with emotions and stress with teaching and learning. 
The implication here is that the personal attributes of the student teachers are important in ensuring that their classroom practice is successful. It also means that they carry their persona to the classroom which might impact their classroom management and teaching either positively or negatively.

\section{System requirements}

Student teachers will not function well, accept, or see the value of mentoring if they do not understand its relevance to their teaching practice or how it will benefit them during WIL. This was the reason why the aim and purpose of the online support were clearly articulated to student teachers. Thus, in following up whether the purpose and aim of the online discussions were achieved, the following questions were asked:

- According to you, were the outcomes of the online debriefing clearly articulated?

- How did the outcomes relate to the CAPS policy?

The responses revealed that $98 \%$ of student teachers agreed that the aim, purpose, and lesson planning were clearly articulated. They also alluded to the fact that the lesson plan was linked to the CAPS FET policy and demystified the confusion they had as they were able to share ideas and assist and give guidance where necessary. Only 2\% either disagreed with the clear articulation of the aim or purpose or were still unsure of lesson plans and the importance thereof.

BJ7: I am not sure if they were achieved. I can't really write a good lesson as a PGCE student, I feel that I'm still weak even after sharing ideas with others on blackboard. I am worried because I need a lesson plan to teach. No teacher can teach without one ... it is worrisome but I will consult my classmates.

Supporting this finding, previous literature also indicated that preservice teachers lack experience regarding planning and managing teaching activities, consequently there is a need for support (Nilsson, 2009). In this regard, Choy, Wong, Lim, and Chong (2013) stated that lesson plans reflect teachers' interpretations of subject matter, as well as the way they adapt instructional materials, influenced by the extent to which the teacher is 
informed about learners' prior knowledge and the topic to be presented. Lessons plans help in observing whether preservice teachers can transform learning theory into practice.

D1S: Yes, and no. ... Yes, I saw the purpose and it was explained in class, yes, my group helped a lot with lesson planning but I'm still struggling here and there with incorporating History concepts in the plan ... that can't be left out ... I can say I am better than before in the previous three years.

In the study of preservice teachers' perceptions of planning, Sahin-Taskin (2017) indicated that lesson plans assisted them to decide on activities to include in their teaching, when to use them, and in being more organised.

SR3 reflected on the blog as follows:

My ability to write a lesson plan based on CAPS principles and the two History concepts has tremendously improved through communicating with my group. All is well with me and my mentor-teacher at school liked my plans, I know I will be able to teach a well-prepared lesson.

In this case, the aims of mentoring, policies, and the teaching and learning plan as a means of creating a conducive learning environment and curricula required by an education system must be clearly articulated. Even so, pedagogical knowledge is essential for executing the system requirements. Thus, the aim and purpose of the online debriefing sessions were clearly articulated to students as "a means of enhancing student-teacher's WIL".

\section{Pedagogical knowledge}

Wiggins and McTighe (2011) argued that content has to be "unpacked" to recognise the big ideas worth understanding and the essential questions worth exposing. Furthermore, they argued that there should be clear evidence of understanding seen when students apply the gained knowledge in authentic contexts - in other words, transference of knowledge to real-life situations.

- The interview schedule and the observations were guided by the following questions:

- What is your understanding of PCK? 
- Name the aspects of the History PCK that you learnt from your group and fellow students as you engaged online?

- To what extent did the online discussion board and the blogging tasks enhance your implementation of History procedural and substantive concepts in your teaching and classroom practice?

The student teachers' responses varied. Most of the PGCE student teachers indicated that the importance of PCK changed their thinking about teaching. RV2 explained: "To me, teaching was just mere talk and textbook explanation, especially teaching History because it was just like past stories".

Others also indicated that they thought that the knowledge of the textbook content would enable them to teach well. In other words, and as Wiggins and McTighe (2010) maintained, understanding must be developed by the learner, in this case the student teacher. Teaching for understanding simplifies meaning making by the student teachers and equips them to successfully transfer their learning to authentic contexts. This was shown when student teachers used illustrations and examples from learners' contexts, current affairs, real-life experiences, and allowed learners to make meaning of the content through linkages with their lives. Furthermore, during the observations of the student teachers' lesson presentations, it was found that there was a great improvement with regard to PCK and implementation of the History concepts - the substantive and procedural concepts both in the lesson and assessment activities.

The student teachers also gave a detailed reflection of their own actions in the classroom. Most student teachers reflected and gave a description of how their teaching style, philosophy, and approach moved from being teacher-centred to learner-centred. They learnt from the analysis of the videos posted by their groups and from the online discussions that direct teaching and dominance of the teacher deprives learners of meaningful learning and should be minimised. According to Darling-Hammond (2006), teachers also need to understand the person and the spirit of every child and find a way to nurture it. They need the skills to construct and manage classroom activities efficiently, communicate well, use technology, and reflect on their practice to learn from and continuously improve it.

MY8: The online discussion helped me to learn about different resources and activities. ... I welcomed the use of blogging tasks as important because they forced me to get deep into learning about things I took for granted such as, learners' role, PCK and the power of technology. 
Other improvements were mentioned as follows:

- $70 \%$ reported on the improvement of taking learners' background knowledge into consideration and incorporating it in their lessons;

- $91 \%$ gained from planning intervention and remediation for learners from the blogs;

- $73 \%$ improved on assessment strategies;

- $81 \%$ reported on improvement in questioning skills, using essential questions, and designing learning activities;

- $8 \%$ said their classroom management skills and dealing with learners' misbehaviour had improved.

This was also evident from their lesson plans and lesson presentations during WIL evaluation. Above all, about $69 \%$ of school mentor-teachers also reported improvement in lesson presentation and classroom management as they observed the student teachers.

\section{Modelling}

Direct modelling in this study was limited to videos and online discussion and blogs. Student teachers saw the modelling of the lesson from the videos recorded by their peers, former students of the institution, and some sampled videos of the school mentors posted on the discussion board by each group. These videos were analysed in terms of good classroom practice. The analysis was based on incorporation of the resources, assessment, classroom management, dealing with learners' behaviour, and interactive teaching strategies. Student teachers had varied experiences in this regard; some felt that the videos limited demonstration and modelling of learners, while others felt that at least they had had a glimpse of what was expected in the classroom. Many of them complained about the quality of the videos with some students feeling that it was more of a performance than an authentic lesson.

Question: "Do you think the lesson presentations and classroom practice were clearly demonstrated through the recorded videos"?

BD16: To a certain extent I did, even though there was a fair endeavour to show the teacherlearner interaction through the video, I felt the video was limiting because I could have love 
to see it done physically.

GY3: I like it, I mean the video analysis of the lesson presentation, management and it is good that there were videos, though these videos, about four, were a bit blurry, I struggled to see some of the things and to hear the discussion in some instances. All the same I can say I gained but wish to have seen more.

ST9: No, no, no ... the screechy noise of one video was really disturbing. I feel as though some of the things were staged for the video, but I did gain here and there ... more so the discussion of the video helped me with classroom management and handling misbehaviour.

\section{Feedback}

The question that was asked was the following: "To what extent do you think the discussion board and blogs' feedback benefited and supported your teaching?”

The responses received in this regard were overwhelmingly positive, in that student teachers appreciated working in groups and were grateful for the support shown by their peers when they asked questions or needed help. It emerged that even those student teachers who would not ordinarily speak in the lectures or answer questions had a voice. The self-reflection and the guided weekly tasks were strongly appreciated by all the student teachers. When researching PGCE students, Frick, Carl, and Beets (2010) found that, through reflection, student teachers can learn about their self in context, and that support and mentoring can be an element that enhances this learning process. The student teachers felt that they were spoilt for choice with regard to feedback from their peers and the lecturer. Some compared the formal lecture feedback which takes several days to weeks to the feedback received within minutes through the online tools. They felt that the discussion board afforded them a spontaneous platform to clarify aspects of a lesson they did not know or understand. The impact of the feedback was also shown in their lesson plans, assessment, reflections, and the type of resources or media used in their lessons.

KK: My lesson planning has improved tremendously from the time I started engaging with my group. At first, I was sceptical but now I know they have my back and I have theirs. Actually, I can say we have each other's backs and we can rely on each other. 
According to Brittin (2005), teachers (mentors) should create a conducive learning atmosphere where student teachers can learn and grow in planning lessons and teach effectively.

BK6: I was struggling with relevant interactive teaching strategies and to answer the blog questions. I then went to the discussion board and vented my frustrations, and ... within few minutes there were more responses than I expected. Imagine if I had to wait for whatever time to ask, I would have waited for ever. ... Blogging for me and reflections played a big role. The History family is great. I am a better teacher and understand teaching strategies, inclusion, diversity and the importance of learners' participation in a lesson because of the blogs and tasks that were given.

Du Plessis (2013) supported this assertion by stating that feedback for students should not be kept until the end of the teaching and learning encounter but should be used to assist them to analyse and reflect continuously during the teaching session or series of sessions.

\section{Discussion and conclusion}

In this article, I have attempted to explore the enhancement of History student teachers' teaching during WIL through the implementation of an online discussion board and blogs using the lens of the five-factor model of mentoring (Hudson, 2010). Although there were a handful of participants who expressed negative views, with some unsure of the success, the overwhelming proportion of participants were positive about the use of digital discussion tools. The study found that student teachers responded positively to the use of the online tools with less than $5 \%$ giving negative feedback. The findings revealed that the face-to-face debriefing was not preferred by most of the participants. Most student teachers felt that it was just a formality and failed to address their immediate needs or enhance their teaching. Student teachers expressed themselves online without fear of judgement or ridicule from their fellow student teachers. More so, peer online scaffolding was appreciated as well as the reflection on personal teaching philosophy. There were also minor challenges highlighted by student teachers such as access to computers and data, especially for those students who were dependent on the government funding for their education. The issue of time was highlighted by student teachers as some of their peers in their respective groups would 
take time to give their input and some would just do it as a formality and give irrelevant information.

With regard to personal attributes, it was found that the student teachers' understanding of the importance of personal attributes and self-concept as History teachers improved. Student teachers gave positive feedback on the improvement in their self-confidence including their self-concept and self-regulation and how this would influence their lessons. The online discussion board helped them see the importance of collegiality, collaboration, and interdependence as future teachers. They highlighted that they were now able to withstand criticism from mentor teachers and fellow student teachers. This is supported by Du Plessis (2013) who stated that a mentoring structure is significant because it develops appropriate competencies for teaching and also affords a strong humanist element in that it focuses on the person of the student teacher.

Furthermore, Sahin-Taskin (2017) emphasised the importance of planning to enhance proper teaching and learning. Thus, with regard to the system requirements, specifically aims, policies, objectives, and lesson planning or planning as a whole, student teachers showed improvement. The relevance and aim of the online tasks and discussions were appreciated by the majority of student teachers. They perceived this platform as an enhancement of their lesson planning in relation to the policy documents and classroom practice. Student teachers were also enabled to think through what they taught, how they taught, and how they could evaluate their teaching (Ruys, Keer \& Aelterman, 2012).

Although there was no direct mentoring, the student teachers appreciated the indirect online modelling through the discussion board and blogs. They emphasised the importance of viewing and analysing the videos by the mentoring schoolteachers and their fellow student teachers, although some students complained about the quality and sound of videos. The pedagogic knowledge gaps showed that they need to be grounded in the PCK. Thus, demonstrations and discussions with mentors and fellow student teachers were invaluable. The majority indicated challenges with the incorporation of the two History concepts, namely, substantive and procedural concepts, although the application of various teaching strategies, classroom management skills, and the incorporation of History aims and skills were successful, despite a few students saying that they had only partially achieved them or did not achieve them.

Lastly, in previous studies using the same five-factor model, it was found that the mentor did not dominate the conversation, but used feedback where necessary, which was the case in this study. Student teachers received varied and timeous feedback from 
their peers and lecturer. The comments of the student teachers as shown in the previous section indicated the need for student teachers to be supported and to have the preference to engage in dialogue with their peers and their institutional instructors during WIL. The participants' responses support the argument by Yusuf (2005), that ICT is a change agent because it changes the content, teaching strategies, and quality of teaching and learning. This ensures a constructivist approach by student teachers who should change and adapt what they learn in lectures to the practical environment. This is supported by Baldwin and Trespalacios (2017) who asserted that online instruction can demonstrate best practices to students which may assist them in the achievement of desired aims and outcomes.

It is true that the advent of technology and particularly the Fourth Industrial Revolution has placed enormous demands and challenges on the education system. Thus, all education sectors must incorporate technology and expose all stakeholders to their use. This means then that the value of technology cannot be taken for granted but should be used by higher education institutions to enhance teaching and learning at ordinary schools. Mentoring does not need to be only done face-to-face, but can also be done online using the fivefactor model. Student teachers can be given an opportunity to be mentored within their own context and at their own pace without fear of judgement even though there might be limitations in terms of accessibility to computers, time, and data.

\section{References}

Baldwin, SJ \& Trespalacios, J 2017. Evaluation instruments and good practices in online education. Online Learning, 21(2).

Beauchamp, C \& Thomas, L 2006, July. Imagination and reflection in teacher education: The development of professional identity from student teaching to beginning practice. In, The First Annual Research Symposium on Imaginative Education. Vancouver: The Imaginative Education Research Group.

Bell, S, Douce, C, Caeiro, S, Teixeira, A, Martín—Aranda, R \& Otto, D 2017. Sustainability and distance learning: A diverse European experience? Open Learning: The Journal of Open, Distance and E-Learning, 32(2):95-102.

Brittin, RV 2005. Preservice and experienced teachers' lesson plans for beginning instrumentalists. Journal of Research in Music Education, 53(1):26-39.

Britzman, DP 1991. Decentering discourses in teacher education: Or, the unleashing of unpopular things. Journal of Education, 173(3):60-80. 
Choy, D, Wong, AF, Lim, KM \& Chong, SNY 2013. Beginning teachers' perceptions of their pedagogical knowledge and skills in teaching: A three-year study. Australian Journal of Teacher Education, 38(5):68-79.

Council on Higher Education 2011. Work integrated learning: Good practice guide. Pretoria: CHE.

Creswell, JW 2007. Qualitative inquiry and research method: Choosing among five approaches. Thousand Oaks: SAGE.

Darling-Hammond, L 2006. Constructing 21st-century teacher education. Journal of Teacher Education, 57(3):300-314.

Department of Education 2011. Curriculum and assessment policy. Pretoria: Government Printers.

Desimone, LM 2009. Improving impact studies of teachers' professional development: Toward better conceptualizations and measures. Educational Researcher, 38(3):181— 199.

Du Plessis, E 2010. Students' experiences of work-integrated learning in teacher education. Progressio, 32(1):206-221.

Du Plessis, E 2013. Mentorship challenges in the teaching practice of distance learning students. The Independent Journal of Teaching and Learning, 8(1):29-43.

Evertson, CM \& Smithey, MW 2000. Mentoring effects on proteges' classroom practice: An experimental field study. The Journal of Educational Research, 93(5):294-304.

Flores, MA \& Day, C 2006. Contexts which shape and reshape new teachers' identities: A multi-perspective study. Teaching and Teacher Education, 22:219-232.

Frick, L, Carl, A \& Beets, P 2010. Reflection as learning about the self in context: Mentoring as catalyst for reflective development in pre-service teachers. South African Journal of Education, 30(3).

Gibbs, G 2007. Data preparation. Analysing qualitative data. London: Sage.

Goel, DR \& Goel, C 2010. Innovations in teacher education. Journal of Engineering, Science and Management Education, 1:24-28.

Hudson, P 2007. Examining mentors' practices for enhancing preservice teachers' pedagogical development in mathematics and science. Mentoring \& Tutoring, 152:201— 217.

Hudson, PB 2010. Mentors report on their own mentoring practices. Australian Journal of Teacher Education, 35(7):30-42.

Hudson, PB 2013. Desirable attributes and practices for mentees: mentor teachers' expectations. European Journal of Educational Research, 2(3):107-118. 
Korthagen, FA 2010. How teacher education can make a difference. Journal of Education for Teaching, 36(4):407-423.

Kvale, S 2007. Doing interviews. The SAGE qualitative research kit. London: Sage.

Mahlangu, VP 2018. The good, the bad, and the ugly of distance learning in higher education. Trends in E-learning: 17-29.

Marshall, C \& Rossman, GB 2016. Designing qualitative research. $2^{\text {nd }}$ edition. Thousand Oaks: Sage.

Merriam, SB 2002. Qualitative research in practice: Examples for discussion and analysis. San Francisco: Jossey-Bass.

Milne, AJ 2006. Designing blended learning space to the student experience. Learning Spaces, 11: 1. https://www.educause.edu/research-and-publications/books/ learning — spaces/chapter_-11—designing_blended—learning—space—student— experience

Moosa, M 2019. Reducing practice—shock: First_year student teachers' experiences of a campus - based teaching practice model. Journal of Education, 77:94-114.

Nilsson, P 2009. From lesson plan to new comprehension: Exploring student teachers' pedagogical reasoning in learning about teaching. European Journal of Teacher Education, 32(3):239-258.

Oduaran, A \& Mokoena, MA 2015. Teacher professional knowledge and teaching in the 21st century. In MJ Taole (Ed.), Teaching practice, perspectives and frameworks. Pretoria: Van Schaik.

Rytivaara, A \& Kershner, R 2012. Co-teaching as a context for teachers' professional learning and joint knowledge construction. Teaching and Teacher Education, 28(7):999-1008.

Ruys, I, Keer, HV \& Aelterman, A 2012. Examining pre-service teacher competence in lesson planning pertaining to collaborative learning. Journal of Curriculum Studies, 44(3):349-379.

Ryan, GW \& Bernard, HR 2003. Data management and analysis methods. In NK. Denzin, \& YS Lincoln (eds): Collecting and interpreting qualitative materials. (2 $2^{\text {nd }}$ ed.) Thousand Oaks: Sage.

Sahin-Taskin, C 2017. Exploring pre-service teachers' perceptions of lesson planning in primary education. Journal of Education and Practice, 8(12):57-63.

Saunders, M, Lewis, P \& Thornhill, A 2009. Research methods for business students. 5th edition. Boston: Prentice Hall. 
Sempowicz, T \& Hudson, P 2011. Analysing mentoring dialogues for developing a preservice teacher's classroom management practices. Australian Journal of Teacher Education, 36(8):1.

Shulman, LS 1986. Those who understand: Knowledge growth in teaching. Educational Researcher, 152:4-14.

Strom, K \& Martin AD 2016. Pursuing lines of flight: Enacting equity-based preservice teacher learning in first-year teaching. Policy Futures in Education, 14(2):252-273.

Van Veen, K, Sleegers, P \& Van de Ven, PH 2005. One teacher's identity, emotions, and commitment to change: A case study into the cognitive-affective processes of a secondary school teacher in the context of reforms. Teaching and Teacher Education, 21(8):917934.

Wiggins, G \& McTighe, J 2010. An introduction to understanding by design. Alexandria: ASCD.

Wiggins, GP \& McTighe, J 2011. The understanding by design guide to creating high - quality units. Alexandria: ASCD.

Yusuf, MO 2005. Information and communication technology and education: Analysing the Nigerian national policy for information technology. International Education Journal, 6(3):316-321. 